\title{
Liver Mucosa-Associated Lymphoid Tissue Lymphoma
}

National Cancer Institute

\section{Source}

National Cancer Institute. Liver Mucosa-Associated Lymphoid Tissue Lymphoma. NCI

Thesaurus. Code C5768.

A rare mucosa-associated lymphoid tissue lymphoma that arises from the liver. It is characterized by the presence of centrocyte-like cells surrounding germinal centers. Lymphoepithelial lesions involving the bile duct epithelium may also be present. 